\title{
The times they are a-changin': cohort effects in aging, cognition, and dementia ${ }^{1}$
}

Two papers recently published in IPG point toward decreasing rates of cognitive decline and dementia in high-income countries. (Dodge et al., 2016; Kosteniuk et al., 2016). These reports join the ranks of a growing body of literature on generational trends, or more, specifically, "cohort effects," in aging, cognitive decline, and dementia.

As noted by Dodge and colleagues (2016), cohort effects are variations in one or more characteristics among groups of individuals born during the same year or other defined era. Any population at a given point in time is made up of multiple sub-cohorts born at different times. These sub-cohorts may have different rates of outcomes such as dementia and mortality. With life expectancy expanding across the planet, growing numbers of individuals are at risk for agerelated conditions like stroke and dementia. Yet, developed countries increasingly show national and regional trends toward decreasing rates of dementia incidence (Rocca et al., 2011; Schrijvers et al, 2012; Qiu et al., 2013; Satizabal et al., 2016), stroke, and stroke mortality (Wolf et al., 1992; Sivenius et al., 2004). If life expectancy increases while the lifetime risk of dementia remains constant across birth cohorts, later cohorts might prolong their dementia-free life span but ultimately experience higher incidence of dementia later in their lives (compression of morbidity) (Langa et al., 2008). On the other hand, if life expectancy increases but survival in dementia also increases, we would see the decline in mortality accompanied by an expansion of morbidity (Hulur et al., 2015).

Kostenyuk and colleagues (2016) examined administrative health databases for the Canadian province of Saskatchewan over eight years and found a significant decrease in the incidence of dementia with a simultaneous increase in the prevalence of dementia. This seeming paradox has a simple explanation. Prevalence (the proportion of the population with the disease at a given time) is a function of two factors: incidence (the rate at which new disease develops in the population over a given period) and duration of survival with disease. In fact, as long as the population remains stable, with

\footnotetext{
${ }^{1}$ The title of this editorial refers to a song of the same name by Bob Dylan, recipient of the 2016 Nobel Prize for Literature.
}

low rates of in- and out-migration, incidence can be estimated by dividing prevalence by duration. As living standards and life expectancy increase, people both with and without dementia live longer; thus, prevalence can remain stable or even increase while incidence could be falling.

Besides trends in prevalence and incidence, cohort effects may also be seen in exposures (putative risk and protective factors) that influence the probability of developing dementia. With regard to an exposure such as educational attainment, the overall population may be heterogeneous while its constituent sub-cohorts may be homogeneous within themselves while differing from one another. True relationships between education and an outcome such as dementia may be masked when examining the population as a whole rather than examining the subcohorts.

The presence of dementia is a categorical (dichotomous) outcome, which requires individuals to have met certain diagnostic criteria and crossed a severity threshold implicit in those criteria. Some groups have chosen to investigate birth cohort effects not in dementia itself, but rather in rates of age-related cognitive decline, which is a continuous outcome, does not depend on whether individuals have crossed a diagnostic threshold, and thus uses more of the available information. Dodge and colleagues (2014; 2016), examined trajectories of age-associated cognitive decline in a pooled sample aged 65+ years, spanning four decade long birth cohorts in an American population with limited education. They found cohort effects such that successive birth cohorts not only had significantly better test performance at the same age, but also less subsequent decline in language, executive function, and attention/processing speed (Dodge et al., 2014) and verbal memory (Dodge et al., 2016). They also found cohort influences on practice effects on the memory test, i.e. successive cohorts showed greater ability to learn from previous testing exposure. These findings parallel the well-known Flynn Effect of IQ increasing over successive generations (Flynn, 1987); however, that effect is not related to ageassociated cognitive change. In this study, although educational attainment increased in successive birth cohorts and was associated with better test 
performance at baseline, it did not explain the cohort effects on cognitive decline.

Other studies have found varying results, depending on the research question, the analytic approach, and the study sample. Thorvaldsson et al. (in press) also reported cohort effects in the Goteborg population-based study in Sweden; studying all participants at ages 70 years, 75 years, and 79 years, they found steeper rates of decline in later-born cohorts. They attributed this finding in part to later-born cohorts having greater cognitive reserve which allows them to delay the onset of measurable decline, but progressing more rapidly once the decline begins. This explanation is congruent with the suggestion by Barreto (2013) that trends toward healthier lifestyle across generations might result in later onset of dementia. Finkel et al. (2007) examined cognitive trajectories over 16 years in members of the Swedish Adoption/Twin Study of Aging, from ages $50-88$ years; they found cohort effects in average performance but not in trajectory over time, perhaps related to the younger age range and relatively short duration of follow-up.

Potential explanations for declining stroke and dementia incidence might include decreases in smoking rates, better management of hypertension, and reductions in several cardiovascular risk factors (Satizabal et al., 2016). However, there are also reported increases in obesity and diabetes with a decline in diabetes complications (Gregg et al., 2014) and an increase in depression (Wittchen and Uhmann, 2010) across successive birth cohorts. Similar factors can be invoked to explain improving trends in cognition, where greater educational attainment may play an even larger role. Other influences to consider include the role of declining mortality and selective survival. Investigators examining neither cognition nor dementia but overall well-being in two large cohorts in Germany and the US found increased well-being in the latest born cohorts, but not among those dying at later ages. They speculate that survival which is "manufactured" by extending life could be expanding morbidity rather than compressing it.

Taken together, the growing evidence suggests a complex and nuanced picture of cohort effects in aging. There are some common trends, but important details vary across existing studies. Incidence of dementia and rates of cognitive decline appear to be decreasing but prevalence of dementia and cognitive impairment remain high in populations of European descent in highincome countries. Service needs will therefore remain high in the foreseeable future. There are no data yet from ethnic minority or economically disadvantaged populations in those countries, let alone from the world's low and middle-countries where populations are aging the most rapidly. There are reasons to be hopeful about the brain health of future generations, as well as reasons for concern. As Jones and Green (2016) point out, it is encouraging to learn that the burden of chronic disease may be malleable, but cautious optimism should not lead to complacency. Careful and sustained investigation of these trajectories in different populations should shed light on their causes and on the potential for extending favorable trends. Planners and policy-makers should welcome new information about changing trends in cognitive decline and dementia, while recognizing that much work remains to be done. The final chapter in this story has yet to be written.

\section{Conflict of interest}

Dr Ganguli is a member of the Scientific Advisory Committee to Biogen, Inc.

\section{MARY GANGULI}

Departments of Psychiatry, Neurology, and

Epidemiology, University of Pittsburgh School of

Medicine and Graduate School of Public Health,

Pittsburgh, PA, USA

Email: GanguliM@upmc.edu

\section{Acknowledgments}

Dr Hiroko Dodge provided valuable input into the writing of this paper. Dr Ganguli receives grant support from grant \# K07AG044395 from the National Institute on Aging, National Institutes of Health, United States Department of Health and Human Services.

\section{References}

Barreto, P. DeS. (2013). Alzheimer's disease: learning from the past, looking to the future. American fournal of Alzheimer's Disease and Other Dementias, 28, 304-305.

Dodge, H. H. et al. (2016). Cohort effects in verbal memory function and practice effects: a population-based study. International Psychogeriatrics. Epub ahead of print. DOI: 10.1017/s1041610216001551.

Dodge, H. H., Zhu, J., Lee, C. W., Chang, C.-C. H. and Ganguli, M. (2014). Cohort effects in age-associated cognitive trajectories. The fournals of Gerontology. Series A, Biological Sciences and Medical Sciences, 69, 687-694.

Finkel, D., Reynolds, C. A., McArdle, J. J. and Pedersen, N. L. (2007). Cohort differences in trajectories of cognitive aging. Fournal of Gerontology, Psychol Sciences, 62, P286-P295.

Flynn, J. R. (1987). Massive IQ gains in 14 nations - what IQ tests really measure. Psychological Bulletin, 101, 171-191. 
Gregg, E. W. et al. (2014). Changes in diabetes-related complications in the United States, 1990-2010. The New England fournal of Medicine, 370, 1514-1523.

Hulur, G., Ram, N. and Gerstorf, D. (2015). Historic improvements in well-being do not hold in late life: birthand death-year cohorts in the US and Germany. Developmental Psychology, 51, 998-1012.

Jones, D. S. and Greene, J. A. (2016). Is dementia in decline? Historical trends and future trajectories. The New England fournal of Medicine, 374, 507-509.

Kosteniuk, J. G. et al. (2016). Simultaneous temporal trends in dementia incidence and prevalence, 2005-2013; a population-based retrospective cohort study in Saskatchewan, Canada. International Psychogeriatrics, 28, 1643-1658.

Langa, K. M. et al. (2008). Trends in the prevaence and mortality of cognitive impairment in the United States: is there evidence of a compression of cognitive morbidity? Alzheimer's E Dementia, 4, 134-144.

Qiu, C., von Strauss, E., Backman, L., Winblad, B. and Fratiglioni, L. (2013). Twenty-year changes in dementia occurrence suggest decreasing incidence in central Stockholm, Sweden. Neurology, 80, 1888-1894.

Rocca, W. A. et al. (2011). Trends in the incidence and prevalence of Alzheimer's disease, dementia, and cognitive impairment in the United States. Alzheimer's \& Dementia 7, 80-93.

Satizabal, C. L., Beiser, A. S., Chouraki, V., Chene, G., Dufouil, C. and Seshadri, S. (2016). Incidence of dementia over three decades in the framingham heart study. The New England fournal of Medicine, 374, 523-532.

Schrijvers, E. M., Verhaaren, B. F., Koudstaal, P. J., Hofman, A., Ikram, M. A., Breteler, M. M. (2012). Is dementia incidence declining?: trends in dementia incidence since 1990 in the rotterdam study. Neurology, 78, 1456-1463.

Sivenius, J. et al. (2004). Continuous 15-year decrease in incidence and mortality of stroke in Finland: the FINSTROKE study. Stroke, 35, 420-425.

Thorvaldsson, V., Karlsson, P., Skoog, J., Skoog, I., Johansson, B. (in press). Better cognition in new birth cohorts of 70 year olds, but greater decline thereafter. fournal of Gerontology, Psychological Sciences, in press.

Wittchen, H.-U. and Uhmann, S. (2010). The timing of depression: an epidemiological perspective. Medicographia, $32,115-125$.

Wolf, P. A. et al. (1992). Secular trends in stroke incidence and mortality. The Framingham Study. Stroke, 23, 1551-1555. 